\title{
Isolation and characterization of aclacinomycin A-non-producing Streptomyces galilaeus (ATCC 31615) mutants
}

\author{
Kristiina Ylihonko, ${ }^{1}$ Juha Hakala, ${ }^{2}$ Jarmo Niemi, ${ }^{1}$ Juhani Lundell ${ }^{3}$ and \\ Pekka Mäntsälä
}

Author for correspondence: Kristiina Ylihonko. Tel: +35821 6338057. Fax: +358216338050.

\footnotetext{
1 Department of Biochemistry and Food Chemistry, University of Turku, Biocity, Tykistökatu 6, FIN-20520 Turku, Finland

2 Centre for Biotechnology, University of Turku, Tykistökatu 6, BioCity, FIN20520 Turku, Finland

3 Leiras Oy, PO Box 415, FIN20101, Turku, Finland
}

\begin{abstract}
Twelve mutants of Streptomyces galilaeus (ATCC 31615) blocked in the production of aclacinomycin A, an anthracycline antibiotic with significant antitumour activity, accumulated intermediates of the biosynthesis of aclacinomycins and several anthracyclines with variant sugar moieties. Three of these aklavinone glycosides have not been described before. Mutant strains H028, H061 and H036 were blocked before the formation of aklavinone, a common intermediate for most anthracyclines. Strain H039 accumulated aklavinone and H026, H035, H038 and H054 had mutations that changed glycosylation of aklavinone. Characterization of the mutants and their products is described.
\end{abstract}

Keywords: Streptomyces galilaeus, aclacinomycin A, anthracycline antibiotics, antibiotic biosynthesis

\section{INTRODUCTION}

Anthracyclines are polyketide antibiotics produced especially by Streptomyces species. Since the isolation of the first anthracycline, rhodomycin, by Brockmann \& Bauer (1950) about 200 natural anthracyclines have been isolated. Anthracyclines consist of an aglycone skeleton (7,8,9,10-tetrahydro-5,12-naphthacene quinone) and a sugar moiety (Fig. 1). The significant antitumour activity of anthracyclines makes them commercially valuable. The demand for new anthracyclines among other antibiotics and the limitation of the traditionally used methods have led to the development of new methods. Hopwood et al. (1985) were the first to produce new antibiotics, so called hybrid antibiotics, by interspecies cloning. Subsequently, the hybrid technique has been successfully applied to producing modified products in other Streptomyces species (McAlpine et al., 1987; Epp et al., 1989; Strohl et al., 1989).

Streptomyces galilaeus produces a complex of aclacinomycin (Acm) A, B and Y, first described by Oki et al. (1975). Aklavinone $(\mathrm{Akn})$, the aglycone of aclacinomycins, is a common precursor for many anthracyclines, including

\footnotetext{
Abbreviations: AcmA, $-B,-N,-T,-Y$, aclacinomycin $A, B, N, T$ (aklavin), $Y$; Acu, L-aculose; Akn, aklavinone; CinA, -B, cinerulose A, B; dF, 2deoxyfucose; Rhn, rhodosamine; Rho, rhodinose.
}

also the daunorubicin and rhodomycin families. Two invariant sugar components in the aclacinomycin complex are rhodosamine (Rhn) and 2-deoxyfucose (dF) (Fig. 1). The third sugar residue is either cinerulose A (CinA), L-aculose (Acu) or cinerulose B (CinB) (Fig. 1). Of the aclacinomycins, $A \mathrm{~cm} A$ is available for clinical use. Studies on production (Oki et al., 1979a), structure (Oki et al., $1979 \mathrm{~b}$ ) and biosynthesis (Kitamura et al., 1981) of aclacinomycins have been reported.

Our interests are to study the biosynthesis and production of anthracycline antibiotics and, as the final goal, to create novel hybrid anthracycline molecules. An essential requirement for such work is a set of bacterial strains with mutations at various steps of antibiotic biosynthesis. These blocked mutants are needed to identify the genes encoding the enzymes in the pathways and also for bioconversion experiments. In this paper we describe the isolation and characterization of several mutants of the aclacinomycin pathway and mutants producing anthracyclines with variant sugar moieties in $S$. galilaeus. Also, a new aspect of the biosynthetic pathway of aklavinone is suggested.

\section{METHODS}

Antibiotics. Aclacinomycin A was kindly supplied by Leiras Oy, Turku, Finland.

Microbial strains. Aclacinomycin-producing Streptomyces 
<smiles>CC1OC(O)CC(N(C)C)C1O</smiles>

Rhodosamine<smiles>CC1OC(O)CCC1=O</smiles>

Cinerulose A<smiles>CC1OC(O)CC(O)C1O</smiles>

2-Deoxyfucose<smiles>CC1OC(O)C=CC1=O</smiles>

Aculose<smiles>CC1CC2OC(O)CC3OC(C)OC(O1)C2O3</smiles>

2-Deoxyfucose-cinerulose B<smiles>CC1OC(O)CCC1O</smiles>

Rhodinose<smiles>CC1OC(O)C(O)CC1=O</smiles>

Cinerulose B

Fig. 1. Chemical structures of the sugar components in aclacinomycins and in aklavinone glycosides.

galilaeus (ATCC 31615) was used as a parent strain from which blocked mutants or variants were induced by mutagenesis. The strains were maintained on solid agar at $4{ }^{\circ} \mathrm{C}$ and as spore suspensions at $-20^{\circ} \mathrm{C}$ or as mycelia stocks at $-70^{\circ} \mathrm{C}$.

Media. ISP4 or ISP2 (Difco) agar media were used for plating mutagenized cell suspensions. Cells were grown in E1-medium, containing glucose $(2 \%, w / v)$, soluble starch $(2 \%, w / v)$, Farmamedia (Trader's Mill Protein Co.) $(0.5 \%)$, yeast extract $(0 \cdot 25 \%), \mathrm{K}_{2} \mathrm{HPO}_{4}(0 \cdot 1 \%), \mathrm{MgSO}_{4} .7 \mathrm{H}_{2} \mathrm{O}(0 \cdot 1 \%), \mathrm{NaCl}(0 \cdot 3 \%)$ and $\mathrm{CaCO}_{3}(0 \cdot 3 \%)$ in tap water $(\mathrm{pH} 7 \cdot 5)$. This medium was also used for production of anthracyclines. TSB medium (Oxoid Tryptone Soya Broth powder, Difco) was used for mutagenization.

Mutagenesis treatment. NTG was used as a mutagen. TSB medium $(50 \mathrm{ml})$ was inoculated from agar slants or spore suspensions and cultivated by shaking (330 r.p.m.) for $2 \mathrm{~d}$ at $28^{\circ} \mathrm{C}$. Homogenized (Sorvall Omni Mixer Homogenizer) and sonicated (MSE $100 \mathrm{~W}$ Ultrasonic Disintegrator, $75 \mathrm{~W}, 5 \mathrm{~s}$ ) culture $(20 \mathrm{ml})$ was diluted to $60 \mathrm{ml}$ with TSB and adjusted to $\mathrm{pH} 8.5$. Half of this suspension was used for NTG treatment. The NTG concentration was $0.5 \mathrm{mg} \mathrm{m}^{-1}$ and incubation was for $0.5 \mathrm{~h}$ at $37^{\circ} \mathrm{C}$ with shaking. This treatment gave a killing frequency of about $90 \%$. Immediately after treatment, the NTG medium was removed by centrifugation, the cells were resuspended in $50 \mathrm{ml}$ TSB and cultivated overnight at $28^{\circ} \mathrm{C}$. After sonication $(75 \mathrm{~W}, 5 \mathrm{~s}$ ) the culture was plated on ISP4 agar and incubated for $5-10 \mathrm{~d}$. Colonies differing from the parent strain in colour were tested for antibiotic production.

Fermentation and product isolation. Selected colonies were

inoculated in $60 \mathrm{ml}$ of the E1 medium in $250 \mathrm{ml}$ Erlenmeyer flasks. Cultivation was at $28^{\circ} \mathrm{C}$ for $5-8 \mathrm{~d}$ in a rotary shaker at 330 r.p.m. The culture was adjusted to $\mathrm{pH} 7$ in a test tube and then extracted with an equal volume of toluene: methanol $(1: 1$, $\mathrm{v} / \mathrm{v})$. The solvent layer $(10-20 \mu \mathrm{l})$ was spotted on Silica Gel 60F-254-plates (Riedel-de Haen, 0.25 mm) and developed with toluene: ethyl acetate:methanol:formic acid $(50: 50: 15: 10$, by vol.). Thicker plates $(0.5 \mathrm{~mm})$ were used for preparative separation of the compounds. AcmA and Akn were used as references, with $R_{F}$ values of $0 \cdot 14$ and $0 \cdot 83$, respectively. Chloroform: methanol $(10: 1, \mathrm{v} / \mathrm{v})$ was used for preparative separation of aglycones. An $R_{F}$ value of 0.46 was obtained for $\mathrm{Akn}$ in this solvent mixture.

HPLC analysis. The purity of the products was determined by HPLC using a Merck's Hitachi apparatus with a Hibar RT $250-40000$ reverse phase analytical column. Acetonitrile: water $(25: 75, \mathrm{v} / \mathrm{v})$ was used as the mobile phase, at a flow rate of $0.5 \mathrm{ml} \mathrm{min}{ }^{-1}$. Samples were dissolved in acetonitrile: water $(1: 1$, $\mathrm{v} / \mathrm{v})$ and $20 \mu \mathrm{l}$ of solution was loaded. Detection was at $A_{254}$ and $A_{436} \mathrm{~nm}$ using a L-4250 UV-VIS-detector.

Hydrolysis and partial hydrolysis of anthracycline glycosides. A solution of about $2 \mathrm{mg}$ anthracycline in $1 \mathrm{ml} 0.5 \mathrm{M} \mathrm{HCl}$ was incubated for $20 \mathrm{~min}$ on a boiling water bath. The aglycones were extracted with an equal volume of toluene: methanol $(1: 1$, $\mathrm{v} / \mathrm{v}$ ). Partial hydrolysis was done in $1 \mathrm{ml} 0.05 \mathrm{M} \mathrm{HCl}$ for $30 \mathrm{~min}$ at $55^{\circ} \mathrm{C}$. After incubation, the mixture was neutralized by adding $0.1 \mathrm{ml}$ sodium phosphate buffer, $\mathrm{pH} 7$. The glycosides were extracted with $2 \mathrm{ml}$ dichloromethane. The products were purified by TLC as described above.

Glycosylation of Akn. Mutants defective in Akn or Akn glycoside production were tested for their ability to glycosylate exogenously added $\mathrm{Akn}$. Saturated $\mathrm{Akn}(1 \mathrm{ml})$ in methanol was added to each culture on the third day of growth and growth was continued for about $24 \mathrm{~h}$, after which the anthracyclines were extracted and the Akn glycosides were determined by TLC as described above.

Oxidoreductase activity. Conversion of AcmA to AcmY was followed by the oxidoreductase method of Yoshimoto et al. (1979). The amount of AcmY formed was measured by TLC.

Cosynthesis. Mutants were cultured in a rotary shaker at $28{ }^{\circ} \mathrm{C}$ as described, and after $2 \mathrm{~d}$ the cultures were combined and growth was continued for an extra day. The products were extracted with toluene: methanol $(1: 1, \mathrm{v} / \mathrm{v})$ and measured by TLC as described above.

General methods. ${ }^{1} \mathrm{HNMR}$ was recorded by a Bruker AM-200 at $200 \mathrm{MHz}$, and MS by a VG Analytical 7070E Organic Mass Spectrometer.

\section{RESULTS}

\section{Isolation of mutants from Streptomyces galilaeus}

To examine the biosynthesis of anthracyclines we isolated a series of $S$. galilaeus mutants blocked in aclacinomycin biosynthesis. The proposed biosynthetic pathway of aclacinomycins is shown in Fig. 2. Colonies differing from the parent strains in colour were picked from ISP4 agar plates after NTG treatment. These colonies were used to inoculate production medium and the production profile of each mutant was measured by TLC; based on these results, eight mutant classes were observed. Characteristic 


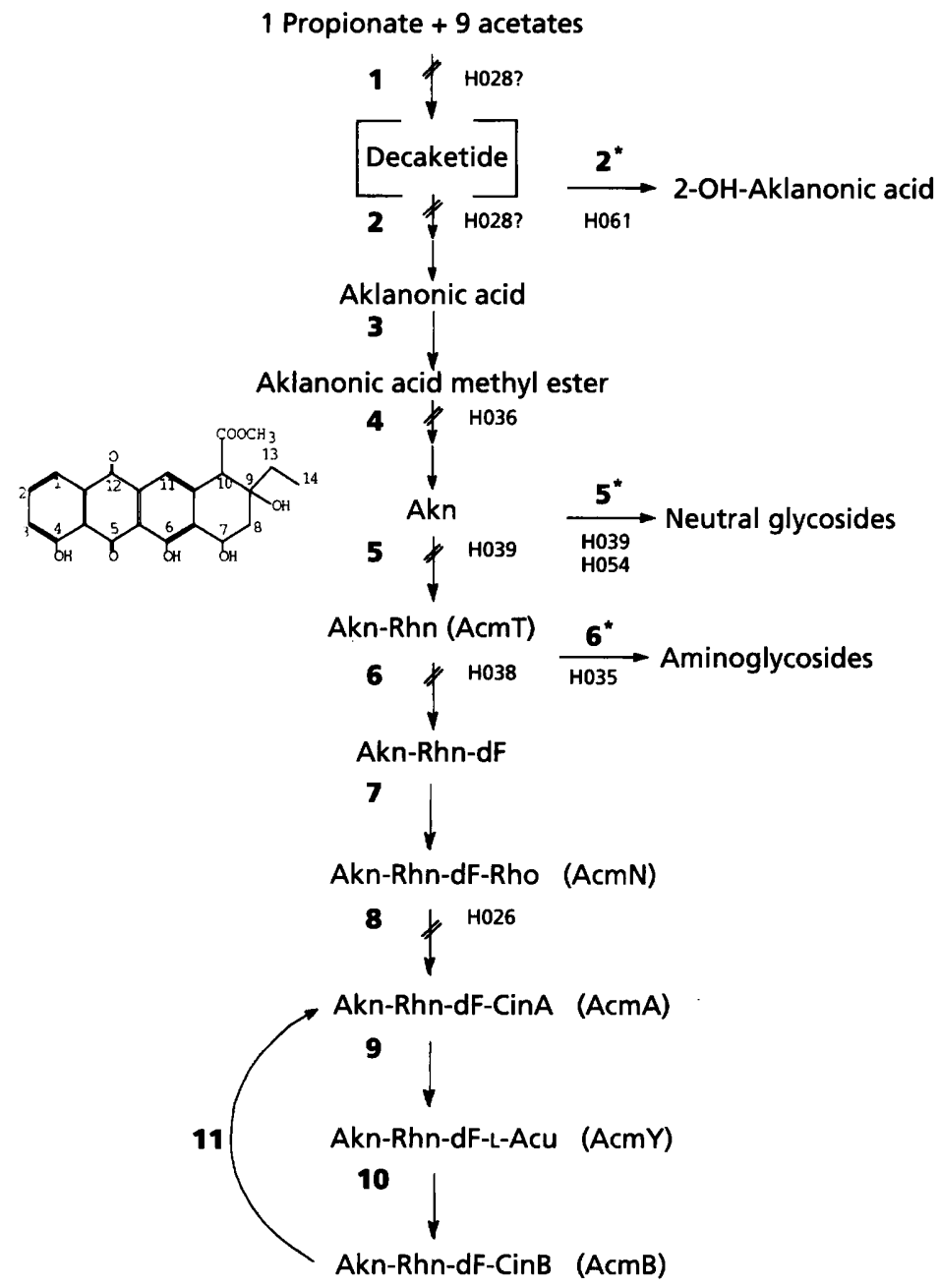

Fig. 2. Proposed biosynthetic pathway of aclacinomycins. The proposed blocks in mutants of S. galilaeus (ATCC 31615) are also shown. The steps are as follows: 1 , condensation; 2, cyclization, aromatization and 2-dehydroxylation; 3, 10-methylation; 4, ring closure and reduction; 5-7, transferring a glycosyl; 8-9, oxidoreduction: 10, reduction: 11, oxidation. The biosynthetic pathway of aklavinone was described by Strohl et al. (1989) and the glycosylation of aklavinone by Oki et al. (1980). * Alternative route for synthesis. Abbreviations: AcmA, $-B,-N,-T,-Y$, aclacinomycin A, B, N, T (aklavin), Y; Acu, L-aculose; Akn, aklavinone; CinA, $-B$, cinerulose A, B; dF, 2-deoxyfucose; Rhn, rhodosamine; Rho, rhodinose.

members are described in Table 1. A pedigree of these mutants is shown in Fig. 3.

Six of the mutants (H028, H036, H061, H068, H069 and $\mathrm{H} 070$ ) were blocked before the formation of aklavinone. A typical colony of the wild-type $S$. galilaeus on ISP4 agar was light yellow with a grey spore pigment. The mutant strains $\mathrm{H} 028$ and $\mathrm{H} 070$ produced no pigment on ISP4 agar or in the E1 medium. H036, H068 and H069 were picked as red colonies, whereas H061 had a brownish colour in its aerial mycelium. None of these strains produced any detectable aclacinomycins or aklavinone. Feeding of the blocked mutants with aklavinone gave aklavinone glycosides as the strains from which they were derived.

\section{Characterization of the mutants}

Mutants blocked before aklavinone. For characterizing the mutants unable to produce aklavinone, the coloured products were identified and bioconversion and cosynthesis experiments were performed. The mutant blocked earlier in the biosynthetic pathway should be able to convert later intermediates to aclacinomycins.

The colourless mutant $\mathrm{H} 028$ converted the products of
$\mathrm{H} 036$ to aclacinomycins but failed to convert the products of $\mathrm{H} 061$ (the reason for this is discussed in more detail below). Cosynthesis of these strains blocked before aklavinone gave aclacinomycins. These results suggested that $\mathrm{H} 028$ is blocked at an early step of the aclacinomycin pathway.

According to the MS spectrum, $\mathrm{H} 061$ produced 2-OHaklanonic acid as the main product. This mutant showed a product profile similar to the previously described $S$. galilaeus strain (ATCC 31671), which is a producer of 2-OH-aklavinone analogues (Matsuzawa et al., 1981). The product from a culture of $\mathrm{H} 036$ was converted to aclacinomycins by $\mathrm{H} 061$, but the products from $\mathrm{H} 061$ were unchanged when $\mathrm{H} 061$ was cultured together with H036, although aclacinomycins were still obtained. The mutation in $\mathrm{H} 061$ is proposed to occur in the gene encoding the 2-dehydroxylation step in the pathway (step 2, Fig. 2).

The products of $\mathrm{H} 036$ were extracted with toluene at $\mathrm{pH} 7$, and a yellow compound isolated from the culture medium was identified as aklanonic acid methyl ester. (Authentic samples of aklanonic acid and aklanonic acid methyl ester were kindly supplied by Dr K. Eckardt, Zentralinstitut für Mikrobiologie und experimentelle 
Table 1. Summary of aclacinomycin A-non-producing S. galilaeus mutants and characterization of their mutations

\begin{tabular}{|c|c|c|c|c|c|}
\hline Mutant & Colour & Main products & $\begin{array}{c}\text { TLC } \\
\left(R_{F}\right. \\
\text { value })\end{array}$ & $\begin{array}{l}\text { Comments/ } \\
\text { reference* }\end{array}$ & $\begin{array}{c}\text { Characterization of } \\
\text { mutation }\end{array}$ \\
\hline H028 & Light & No coloured compound & - & - & $\begin{array}{l}\text { Mutation before first } \\
\text { stable intermediate }\end{array}$ \\
\hline $\mathrm{H} 070$ & Light & No coloured compound & - & - & $\begin{array}{l}\text { Mutation before first } \\
\text { stable intermediate }\end{array}$ \\
\hline H061 & $\begin{array}{l}\text { Brownish } \\
\text { yellow }\end{array}$ & 2-OH-Aklanonic acid & $0 \cdot 36$ & Known (1) & $\begin{array}{l}\text { 2-dehydroxylase } \\
\text { deficient mutant }\end{array}$ \\
\hline $\mathrm{H} 036$ & Red & $\begin{array}{l}\text { Aklanonic acid methyl } \\
\text { ester }\end{array}$ & 0.72 & Known (2) & $\begin{array}{l}\text { Mutation in ring } \\
\text { closure }\end{array}$ \\
\hline $\mathrm{H} 068$ & Red & $\begin{array}{l}\text { Aklanonic acid methyl } \\
\text { ester }\end{array}$ & $0 \cdot 72$ & Known (2) & $\begin{array}{l}\text { Mutation in ring } \\
\text { closure }\end{array}$ \\
\hline $\mathrm{H} 069$ & Red & $\begin{array}{l}\text { Aklanonic acid methyl } \\
\text { ester }\end{array}$ & 0.72 & Known (2) & $\begin{array}{l}\text { Mutation in ring } \\
\text { closure }\end{array}$ \\
\hline $\mathrm{H} 039$ & $\begin{array}{l}\text { Bright } \\
\text { yellow }\end{array}$ & $\begin{array}{l}\text { (1) Aklavinone } \\
\text { (2) Akn-Rho-Rho }\end{array}$ & $\begin{array}{l}0 \cdot 83 \\
0 \cdot 74\end{array}$ & $\begin{array}{l}\text { Known (3) } \\
\text { New }\end{array}$ & Loss of amino sugar \\
\hline $\mathrm{H} 038$ & Yellow & Akn-Rhn & $0 \cdot 13$ & Known (4) & $\begin{array}{l}\text { Unknown mutation } \\
\text { in glycosylation }\end{array}$ \\
\hline $\mathrm{H} 026$ & Yellow & Akn-Rhn-dF-Rho & $0 \cdot 11$ & Known (5) & $\begin{array}{l}\text { Oxidoreductase } \\
\text { deficient }\end{array}$ \\
\hline H035 & Yellow & Not yet identified & $\begin{array}{l}0 \cdot 04 \\
0 \cdot 07 \\
0 \cdot 11\end{array}$ & Unknown & $\begin{array}{l}\text { Unknown mutation } \\
\text { in glycosylation }\end{array}$ \\
\hline $\mathrm{H} 054$ & $\begin{array}{l}\text { Bright } \\
\text { yellow }\end{array}$ & $\begin{array}{l}\text { (1) Akn-Rho-dF-CinA } \\
\text { (2) Akn-dF-dF-CinA } \\
\text { (3) Akn-dF-Rho-Rho } \\
\text { (4) Akn-Rho-dF } \\
\text { (5) Akn-dF-dF }\end{array}$ & $\begin{array}{l}0.69 \\
0.63 \\
0.58 \\
0.54 \\
0.43\end{array}$ & $\begin{array}{l}\text { New } \\
\text { Known (1) } \\
\text { Known (1) } \\
\text { New } \\
\text { Known (1) }\end{array}$ & Loss of amino sugar \\
\hline $\mathrm{H} 042$ & Yellow & $\begin{array}{l}A \mathrm{cmA} \\
\mathrm{AcmY} \\
\mathrm{AcmB}\end{array}$ & $\begin{array}{l}0 \cdot 14 \\
0 \cdot 18 \\
0 \cdot 28\end{array}$ & $\begin{array}{l}\text { Known (6) } \\
\text { Known (6) } \\
\text { Known (6) }\end{array}$ & $\begin{array}{l}\text { Overproducer of } \\
\text { AcmB }\end{array}$ \\
\hline
\end{tabular}

*(1) Matsuzawa et al. (1981); (2) Eckardt et al. (1985a); (3) Gordon et al. (1960); (4) Kumar et al. (1977); (5) Oki et al. (1977); (6) Oki et al. (1975).

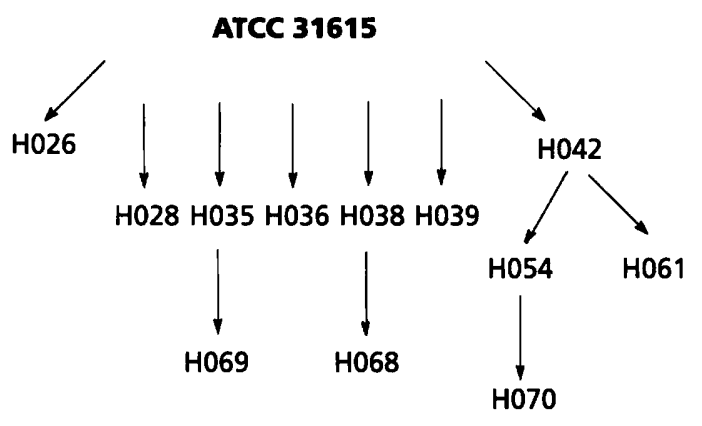

Fig. 3. A pedigree of mutants obtained by mutagenization of S. galilaeus (ATCC 31615).

Therapie, Jena, Germany.) In addition to aklanonic acid methyl ester at least five yellow or red products were isolated from the culture of H036. On the basis of MS spectra, these compounds were identified as condensation products of aklanonic acid methyl ester. Aklanonic acid has been described as an early intermediate in the biosynthesis of anthracyclines (Eckardt et al., 1985a).

H028 effectively converted aklanonic acid methyl ester isolated from $\mathrm{H} 036$ to aclacinomycins. Also, H061 converted the product of $\mathrm{H} 036$ to aclacinomycins. Cosynthesis of $\mathrm{H} 028$ and $\mathrm{H} 036$ or $\mathrm{H} 061$ and $\mathrm{H} 036$ gave aclacinomycins. From the toluene extracts of the cocultures, only the products of $\mathrm{H} 036$ were converted to aclacinomycins.

Based on the products of H036, co-culture experiments and bioconversion behaviour, we conclude that $\mathrm{H} 036$ is defective in the structural gene encoding closure of the fourth ring in aklavinone. The probability that this mutation occurred in a single structural gene is supported by the finding of two similar mutants, $\mathrm{H} 068$ and $\mathrm{H} 069$ by a single mutagenization treatment of two mutant strains, $\mathrm{H} 035$ and $\mathrm{H} 038$, which produce a variety of different aklavinone glycosides. 
Table 2. MS data of the aklavinone neutral glycosides obtained from S. galilaeus mutants $\mathrm{HO} 9$ and H054

\begin{tabular}{|c|c|}
\hline Compound & MS data \\
\hline H039-1 & $\begin{array}{l}\mathrm{M}^{+} \text {Akn-Rho-Rho (641); Akn-Rho (526); Akn } \\
(412) ;-\left(\mathrm{H}_{2} \mathrm{O}\right)(376)\end{array}$ \\
\hline H054-1 & $\begin{array}{l}\mathrm{M}^{+} \text {Akn-Rho-dF-CinA (768); Akn-Rho (526); Akn- } \\
\left(\mathrm{H}_{2} \mathrm{O}\right)(376)\end{array}$ \\
\hline $\mathrm{H} 054-2$ & $\begin{array}{l}\left.\mathrm{M}^{+} \text {Akn-dF-dF-CinA (784); -( } \mathrm{H}_{2} \mathrm{O}\right)(766) ; \mathrm{Akn}-\mathrm{dF} \\
(543) ; \mathrm{Akn}-\left(\mathrm{H}_{2} \mathrm{O}\right)(376)\end{array}$ \\
\hline $\mathrm{H} 054-3$ & $\begin{array}{l}\mathrm{M}^{+} \text {Akn-dF-Rho-Rho (770); Akn-dF-Rho (656); } \\
\text { Akn-dF (542); Akn- }\left(\mathrm{H}_{2} \mathrm{O}\right)(376)\end{array}$ \\
\hline H054-4 & $\begin{array}{l}\mathrm{M}^{+} \text {Akn-Rho-dF (656); Akn-Rho (526); Akn (412); } \\
-\left(\mathrm{H}_{2} \mathrm{O}\right)(376)\end{array}$ \\
\hline $\mathrm{H} 054$ & $\begin{array}{l}\mathrm{M}^{+} \text {Akn-dF-dF (672); Akn-dF (542); Akn- }\left(\mathrm{H}_{2} \mathrm{O}\right) \\
\quad(376)\end{array}$ \\
\hline
\end{tabular}

Mutants producing neutral glycosides. H039 accumulated unglycosylated aklavinone as the main product. When cultivation was continued for more than 5-7 d, a glycosylated compound was also obtained. Acid hydrolysis gave aklavinone as an aglycone. According to the MS spectrum, the molecular mass of this compound was $641 \mathrm{Da}$ (Table 2). Based on hydrolysis, molecular mass and fragmentation analysis, the structure of this compound is Akn-Rho-Rho.

H054 grew as a bright yellow colony on ISP4 agar. This mutant produced five main products, which gave aklavinone after hydrolysis. Partial hydrolysis of the products was not successful, but also yielded aklavinone. Extraction by toluene over a wide $\mathrm{pH}$ range and the $\mathrm{R}_{\mathrm{F}}$ values obtained $(0.69,0.63,0.58,0.54,0.43)$ suggest that these compounds have neutral sugars instead of amino sugars which are characteristic of the products in the wild-type strain. The structures of the products were determined by mass spectroscopy (Table 2). The stereochemistry of the sugar moiety was deduced by analogy to aminoglycosides. The main metabolites are as follows: H054-1, Akn-Rho-dF-CinA; H054-2, Akn-dFdF-Cin A; H054-3, Akn-dF-Rho-Rho; H054-4, Akn-RhodF; H054-5, Akn-dF-dF.

Mutants producing aminoglycosides. Stepwise glycosylation of aklavinone to aclacinomycins was described by Oki et al. (1980). The model of glycosylation based on the mutants obtained by screening (Fig. 2) correlates well with the glycosylation pathway of aklavinone proposed by Oki et al. (1980). The product of $\mathrm{H} 038$ was identified as Acm T, also known as aklavin (Kumar et al., 1977), by ${ }^{1}$ HNMR. AcmT is the first glycosylated intermediate in the pathway. Acid hydrolysis of aklavin gave aklavinone as an aglycone and rhodosamine as a sugar residue. $\mathrm{H} 038$ also exhibits oxidoreductase activity, converting AcmA to AcmY.

$\mathrm{H} 026$ produced an anthracycline $\mathrm{AcmN}$, whose structure was described by Oki et al. (1979b). A specific oxidoreductase is responsible for conversion of $\mathrm{AcmN}$ to AcmA and further to AcmY (Yoshimoto et al., 1979).
Neither the cells nor the culture supernatant of $\mathrm{H} 026$ converted $A \mathrm{cmA}$ to $A \mathrm{cmY}$, but with the supernatant of the blocked mutant (H028) AcmN from $\mathrm{H} 026$ was converted to $A \mathrm{~cm} Y$ and $A \mathrm{~cm} A$, suggesting that $A \mathrm{cmN}$ is a true intermediate in AcmA biosynthesis. It is probable that $\mathrm{H} 026$ has a mutation in the structural gene encoding the oxidoreductase.

H035 showed a different product profile from the wildtype (ATCC 31615) in TLC analysis: $R_{F}$ values of 0.04 , 0.07 and 0.11 for the main compounds were obtained. Acid hydrolysis of these compounds gave aklavinone as an aglycone and partial hydrolysis of products from $\mathrm{H} 035$ gave AcmT. The $R_{F}$ values of the hydrolysed, partially hydrolysed and non-hydrolysed products suggest that the synthesis of these three products occurs by a branch from the AcmA pathway in step 6 (Fig. 2). However, possible additional sugar moieties have not yet been identified.

Besides these unidentified aminoglycosides, H035 produced a yellow compound which in hydrolysis and in extraction behaved as an aglycone. Based on MS data the structure was a dimer of aklavinone. The dimer gave mass peaks at $\mathrm{M}^{+}(789), \mathrm{M}^{+}-\mathrm{H}_{2} \mathrm{O}(771)$, and $\mathrm{M}^{+}-\left(\mathrm{Akn}+\mathrm{H}_{2} \mathrm{O}\right)(376)$. A similar aklavinone dimer was prepared from AcmA by hydrogenolysis or by reductive cleavage with NADPH (Oki et al., 1979b).

\section{DISCUSSION}

Three mutants blocked before aklavinone were found in these screening programmes. Two of the possible classes of mutants blocked before aklavinone and producing coloured intermediates according to the proposed pathway were not obtained. One of the missing mutants could be a producer of aklanonic acid (Eckardt et al., 1985a) and the other a producer of aklaviketone (Eckardt et al., 1988). Aklanoic acid is the intermediate that is methylated to form aklanonic acid methyl ester and a cyclization product is aklaviketone, which is the last intermediate before aklavinone.

Based on their product profile, cosynthesis and biotransformation behaviour of the mutants $\mathrm{H} 028$ and H036 were as expected. Unexpectedly, the coloured products of $\mathrm{H} 061$ remained unchanged in the experiments performed. An inability of 2-OH-aklanonic acid to enter the cells is unlikely, because Eckardt et al. (1985b) and Wagner et al. (1984) succeeded in converting aklanonic acid to aglycones by biotransformation.

We propose that 2-OH-aklanonic acid is a shunt product; the true intermediate in the aklavinone pathway produced by $\mathrm{H} 061$ could be an uncoloured and perhaps unstable compound.

Although the products of $\mathrm{H} 061$ were similar to those of $S$. galilaeus (ATCC 31671), we failed to find 2-OH-aklavinone or any glycosylated compounds from highly concentrated extracts of H061 culture broths. However, exogenously added aklavinone was converted to aclacinomycins. Yoshimoto et al. (1981) succeeded in converting 2-OHaklavinone to 2-OH-aclacinomycin A by blocked mutants. By fusing protoplasts from a mutant producing 
2-OH-aklavinone and from an early blocked mutant, it has also been possible to produce 2-OH-aclacinomycins (Yoshimoto et al., 1984). In these cases glycosylation was successful, and glycosyltransferase accepted 2-OHaklavinone as substrate. We suggest that 2-OHaklavinone, which was not present in cultures of H061, is also a shunt product and that the enzyme responsible for ring closure to make the aglycone skeleton has a high specificity, closure failing if a hydroxyl group is attached to position 2 . However, different culture conditions could favour the formation of 2-OH-aklavinone either enzymically or spontaneously, or the mutants derived from S. galilaeus (ATCC 31133), albeit having the same product profile as $\mathrm{H} 061$ in conditions described in Methods, have a different enzyme specificity.

H039 and H054 produce aklavinone glycosides with rhodinose as the first sugar residue, the compounds which were not described before. Further mutagenesis of $\mathrm{H} 054$ gave a mutant, $\mathrm{H} 070$, which was similar to $\mathrm{H} 028$. Feeding of this mutant with aklavinone gave neutral glycosides, as H054. This blocked mutant may be used as a converter strain for different aglycones to produce novel aglycone glycosides.

Further mutagenization of $\mathrm{H} 035$ and $\mathrm{H} 038$ gave aklanonic acid methyl ester producers, $\mathrm{H} 069$ and $\mathrm{H} 068$, respectively. Feeding of these mutants with aklavinone provided similar glycosylation profiles as their parent strain. These mutants are possible converter strains for aglycones to synthesize a variety of anthracyclines because their own products were easily separated from aminoglycosides.

We noticed that $\mathrm{H} 026$ is an industrially interesting mutant. Conversion of $A \mathrm{cmB}$ to $\mathrm{AcmA}$ was detected in the culture broth of H026. The same activity is also present in cultures of wild-type $S$. galilaeus, but it is masked by the activity of oxidoreductase (Hoshino et al., 1983). The fact. that $\mathrm{H} 026$ converted $\mathrm{AcmB}$ to AcmA but did not catalyse the reverse reaction ( $A \mathrm{~cm} A$ to $A \mathrm{cmY}$ to $A \mathrm{cmB}$ ) could be advantageous for industrial production of the valuable product, $A \mathrm{cmA}$. We obtained more $A \mathrm{cmB}$ than $A \mathrm{cmA}$ from over-producing mutant cultures (e.g. H042), but failed to find any stable strain producing large amounts of AcmA. To increase the yield of AcmA, a H026-type strain could be used as a biocatalyst in an AcmB-over-producing mutant culture.

The exact nature of the mutations in H039, H054, H035 and $\mathrm{H} 038$ was not clear. The metabolites of $\mathrm{H} 039$ and H054 contained no amino sugar. It is possible that the mutation occurred in the genes encoding glycosyltransferase in $\mathrm{H} 039$ that prevents glycosylation. In contrast, alterations in carbohydrate metabolism (for example shortage of thodosamine) could result in addition of different sugar moieties to the aglycone. In any case these two strains have a different mutation in the glycosylation system.

H026 could be classified as an oxidoreductase-deficient mutant. Other mutations in various strains producing aminoglycosides may be concerned with conversion of sugars or in the glycosyltransferase reaction. In the case of $\mathrm{H} 038$, the addition of deoxyfucose to the glycoside residue of aklavin is prevented in an unknown way. A shortage of deoxyfucose or inactivity of the glycosyltransferase may be responsible for this failure.

\section{ACKNOWLEDGEMENTS}

This research was supported by the Finnish Academy of Sciences. We thank Dr K. Lampi (Leiras Oy, Finland) for valuable advice and helpful information, Drs M. Reunanen (Åbo Akademi, Finland), H. Nikander (Leiras Oy, Finland) and J. Vepsäläinen (University of Kuopio, Finland) for recording the spectrum data, and Professor D. A. Hopwood (John Innes Institute, Norwich, UK) for critical reading of the manuscript.

\section{REFERENCES}

Brockmann, H. \& Bauer, K. (1950). Rhodomycin, ein rotes Antibioticum aus Actinomyceten. Naturwissenscbaften 37, 492-493.

Eckardt, K., Tresselt, D., Schumann, G., Ihn, W. \& Wagner, C. (1985a). Isolation and chemical structure of aklanonic acid, a potential early intermediate in the biosynthesis of anthracyclines. $J$ Antibiot 38, 1034-1039.

Eckardt, K., Schumann, G., Gräfe, U., Ihn, W., Wagner, C., Fleck, W. \& Thrum, H. (1985b). Preparation of labelled aklanonic acid and its bioconversion to anthracyclinones by mutants of Streptomyces griseus. J Antibiot 38, 1096-1097.

Eckardt, K., Schumann, G., Tresselt, D. \& Ihn, W. (1988). Biosynthesis of anthracyclinones: isolation of a new early cyclization product aklaviketone. $J$ Antibiot 41, 788-793.

Epp, J., Huber, M., Turner, J., Goodson, T. \& Schoner, B. (1989). Production of hybrid macrolide antibiotic in Streptomyces ambofaciens and Streptomyces lividans by introduction of a cloned carbomycin biosynthetic gene from Streptomyces thermotolerans. Gene 85, 293-301.

Gordon, J., Jackman, L., Ollis, W. \& Sutherland, I. (1960). Aklavinone. Tetrabedron Lett 8, 28-34.

Hopwood, D. A., Malpartida, F., Kieser, H., Ikeda, H., Duncan, J., Fujii, I., Rudd, B., Floss, H. \& Omura, S. (1985). Production of ' hybrid' antibiotics by genetic engineering. Nature 314, 642-644.

Hoshino, T., Sekine, Y. \& Fujiwara, A. (1983). Microbial conversion of anthracycline antibiotics. I. Microbial conversion of aclacinomycin B to aclacinomycin A. J Antibiot 36, 1458-1462.

Kitamura, I., Tobe, H., Yoshimoto, A., Oki, T., Naganawa, H., Takeuchi, T. \& Umezawa, H. (1981). Biosynthesis of aklavinone and aclacinomycins. J Antibiot 34, 1498-1500.

Kumar, V., Remers, W. \& Grulich, R. (1977). The structure of aklavin. Antibiot 30, 881-882.

Matsuzawa, Y., Yoshimoto, A., Shibamoto, N., Tobe, H., Oki, T., Naganawa, H., Takeuchi, T. \& Umezawa, H. (1981). New anthracycline metabolites from mutant strains of Streptomyces galilaeus MA144-M1 II. Structure of 2-hydroxyaklavinone and new aklavinone glycosides. J Antibiot 34, 959-964.

McAlpine, J., Tuan, J., Brown, D., Grebner, K., Whittern, D., Buko, A. \& Katz, L. (1987). New antibiotics from genetically engineered actinomycetes. I. 2-Norerythromycins, isolation and structural determinations. J Antibiot 40, 1115-1122.

Oki, T., Matsuzawa, Y., Yoshimoto, A., Numata, K., Kitamura, I., Hori, S., Takamatsu, A., Umezawa, H., Ishizuka, M., Naganawa, H., Suda, H., Hamada, M. \& Takeuchi, T. (1975). New antitumor antibiotics, Aclacinomycins A and B. J Antibiot 28, 830-834.

Oki, T., Shibamoto, N., Matsuzawa, Y., Ogasawara, T., Yoshimoto, A., Kitamura, I., Inui, T., Naganawa, H., Takeuchi, T. \& Umezawa, H. (1977). Production of nineteen anthracyclic 
compounds by Streptomyces galilaeus MA144-M1. I Antibiot 30, 683-687.

Oki, T., Kitamura, I., Yoshimoto, A., Matsuzawa, Y., Shibamoto, N., Ogasawara, T., Inui, T., Takamatsu, A., Takeuchi, T., Masuda, T., Hamada, M., Suda, H., Ishizuka, M., Sawa, T. \& Umezawa, H. (1979a). Antitumor anthracycline antibiotics, aclacinomycin $A$ and analogues. I. Taxonomy, production, isolation and physicochemical properties. $J$ Antibiot 32, 791-800.

Oki, T., Kitamura, I., Matsuzawa, Y., Shibamoto, N., Ogasawara, T., Yoshimoto, A., Inui, T., Naganawa, H., Takeuchi, T. \& Umezawa, H. (1979b). Antitumor anthracycline antibiotics, aclacinomycin A and analogues. II. Structural determination. $J$ Antibiot 32, 801-819.

Oki, T., Yoshimoto, A., Matsuzawa, Y., Takeuchi, T. \& Umezawa, H. (1980). Biosynthesis of anthracycline antibiotics by Streptomyces galilaeus. I. Glycosidation of various anthracyclinones by an aclacinomycin-negative mutant and biosynthesis of aclacinomycins from aklavinone. J Antibiot 33, 1331-1341.

Strohl, W., Bartel, P., Connors, N., Zhu, C.-B., Dosch, D., Beale, J., Jr, Floss, H., Stuzman-Engwall, K., Otten, S. \& Hutchinson, C. R.

(1989). Biosynthesis of natural and hybrid polyketides by anthracycline-producing Streptomycetes. In Genetics and Molecular Biology of Industrial Microorganisms, pp. 68-84. Edited by C. Hershberger, S. Queener \& G. Hegeman. Washington, DC: American Society for Microbiology.

Wagner, C., Eckardt, K., Schumann, G., Ihn, W. \& Tresselt, D. (1984). Microbial transformation of aklanonic acid, a potential early intermediate in the biosynthesis of anthracyclines. J Antibiot 37, 691-692.

Yoshimoto, A., Ogasawara, T., Kitamura, I., Oki, T., Inui, T., Takeuchi, T. \& Umezawa, H. (1979). Enzymatic conversion of aclacinomycin A to $\mathrm{Y}$ by a specific oxidoreductase in Streptomyces. $J$ Antibiot 32, 472-481.

Yoshimoto, A., Matsuzawa, Y., Oki, T., Takeuchi, T. \& Umezawa, H. (1981). New anthracycline metabolites from mutant strains of Streptomyces galilaeus MA144-M1 I. Isolation and characterization of various blocked mutants. $J$ Antibiot 34, 951-958.

Yoshimoto, A., Tobe, H., Ishikura, T., Umezawa, H. \& Takeuchi, T. (1984). US Patent 4474945 (Oct. 2, 1984).

Received 29 September 1993; revised 6 December 1993; accepted 15 December 1993. 